\title{
Condição juvenil e a participação política no Brasil
}

\section{Lucas Toshiaki Archangelo Okado Ednaldo Aparecido Ribeiro}

\section{Resumo}

Este trabalho tem por objetivo verificar os impactos dos marcadores que caracterizam o fim da juventude e a entrada na vida adulta no ativismo político brasileiro. Tomam-se como referência os estudos sobre ciclos de vida que afirmam que, apesar da permanência residual de valores originados na socialização primária, o desempenho de novos papéis sociais originam novos repositórios de socialização, uma vez que a política é um domínio da vida responsivo a eles. Utilizando dados do projeto Latinobarômetro coletados em 1995, 2000 e 2005, procuramos verificar o impacto da condição juvenil, definida pelo casamento e o desempenho de uma atividade produtiva, nos repertórios convencionais e não convencionais de participação política. Os resultados encontrados apontam que a condição juvenil oferece restrições e oportunidades para a participação política, de acordo com o tipo de repertório analisado. Desta forma concluímos que a participação convencional impõem mais custos participativos, portanto menos acessível aos jovens, enquanto a participação não convencional seria mais plural, proporcionando menos diferenças no acesso de jovens e adultos neste tipo de repertório.

Palavras-chave: Juventude. Condição Juvenil. Participação Política. Comportamento Político. Ciclo de Vida.

\section{Abstract}

This paper aims to determine the impacts of the markers that characterize the end of youth and the entrance into adulthood in the Brazilian political activism. Are taken as

\section{Sobre os autores}

Lucas Toshiaki Archangelo Okado é aluno do programa de pós-graduação (doutorado) em Ciência Política da Universidade Federal do Paraná. Membro do Núcleo de Pesquisa em Participação Política da Universidade Estadual de Maringá (NUPPOL/UEM). Email: lucas.okado@gmail.com.

Ednaldo Aparecido Ribeiro é professor da Universidade Estadual de Maringá e do Programa de Pós-graduação em Ciência Política da Universidade Federal do Paraná. Membro do Núcleo de Pesquisa em Participação Política da Universidade Estadual de Maringá (NUPPOL/UEM). Email: ednaldorip@uol.com.br. 
reference studies about life cycles that have affirmed, that despite the persistence of residual values originated in the primary socialization, the performance of new social roles originate new repositories of socialization, since politics is a domain-specific of life and responsive to it. Using data collected Latinbarometer project in 1995, 2000 and 2005 , we assessed the impact of youth condition, defined by marriage and performance of a productive activity in conventional and unconventional political participation repertoires. The results indicate that the juvenile condition offers constraints and opportunities for political participation, according to the type of repertoire analyzed. Thus we conclude that conventional participation participatory impose more costs therefore less accessible to young people, while unconventional participation would be plural, providing fewer differences in access of young people and adults in this kind of repertoire.

Keywords: Youth.Youth Condition. Political Participation. Political Behavior. Life Cycle.

Artigo recebido em 6 de janeiro de 2015; aceito para publicação em 23 de fevereiro de 2015.

\section{Introdução}

Recentes pesquisas sobre ativismo político identificam que as coortes etárias que se enquadram no estrato populacional que definimos como juventude tem se engajado cada vez menos nos repertórios convencionais de participação. O comparecimento dos jovens nas eleições tem diminuído ao longo do tempo, bem como seu envolvimento com a militância partidária.

Para além da simples constatação, essas investigações tem apresentado explicações para esse comportamento. Para Putnam (2001), por exemplo, a juventude norte americana tem se tornado apática e cínica em razão do seu afastamento das atividades de caráter comunitário e associativo, o que teria diminuído o estoque de capital social presente na sociedade, importante recurso participativo. Outra interpretação recorrente é a de que o jovem têm se afastado da política por conta dos processos de transição distintos e incertos em relação aos seus pais e avós, levando-os para longe dos assuntos públicos (Henn, et al., 2002). Em uma perspectiva mais otimista, alguns estudiosos enfatizam a transformação no modelo de cidadania adotado pelos jovens, que prefeririam a uma postura mais engajada (Dalton, 2009), ampliando o leque de repertórios utilizados para efetuar a sua participação política (Norris, 2002). 
Todos estes estudos demonstram a constituição de distintos padrões de envolvimento político entre jovens e adultos nos últimos anos. Ainda que baseados em premissas e conclusões diferentes, estes autores afirmam que os jovens se afastaram da participação convencional, ou seja, àquela ligada aos canais políticos institucionais, como o voto, o envolvimento em campanhas eleitorais e o ativismo partidário; e se aproximado de modalidades não convencionais, como as atividades de protesto, mais diretas e com pouca relação com os mecanismos institucionais de representação nas democracias contemporâneas. Desta forma, enquanto os indivíduos adultos enfatizam um aspecto da cidadania baseado na responsabilidade (Dalton, 2009), os jovens repensam o ativismo político ao buscar formas de atuação através de repertórios orientados por causa (Norris, 2003). Ainda que a variedade de abordagens explicativas seja considerável é possível distinguir dois grandes grupos quando se trata de identificar as causas dessa mudança de padrão participativo entre os mais jovens.

De um lado podemos localizar um conjunto de proposições que enfatizam os processos de sobreposição geracional. Novamente Putnam (2001) é referência importante ao afirmar que a apatia e o cinismo juvenil estariam associados a diferenças significativas nos valores manifestos pelas distintas gerações. Outro grupo de pesquisadores, ligados aos estudos sobre pós-materialismo e cidadania crítica, tem apontado que essa reorientação juvenil para o novo ativismo é mais um reflexo de uma mudança mais ampla nos valores que se concretiza na sobreposição de uma geração sobre a outra (Inglehart e Welzel, 2005; Dalton, 2009; Norris, 2003).

Do outro lado, podem ser dispostos os estudos que destacam os efeitos oriundos dos ciclos de vida. Nessa perspectiva, as diferenças entre a participação de jovens e adultos estariam relacionadas aos processos de transição inerentes ao curso da vida, que seriam responsáveis por oferecer oportunidades ou constrangimentos de recursos participativos, gerando as diferenças na forma como jovens e adultos efetivam o seu envolvimento com a vida pública (Kinder, 2006; Stoker e Jennings, 1995; Highton e Wolfinger, 2001; Verba, Scholzman e Brady, 1995). Combinando a preocupação com esse processo de transição com fatores conjunturais, alguns estudos enfatizam os chamados efeitos de período. $\mathrm{Na}$ Perspectiva de Henn et al. (2005), as condições sob as quais estão 
imersos os processos de transição da juventude para a vida adulta podem gerar ou potencializar uma série de incertezas, exigindo recursos que outrora poderiam ser utilizados para se efetivar a participação política.

Todo este debate tem ocupado a agenda de pesquisadores, mas a ênfase dada até então recai sobre as democracias mais consolidadas, havendo poucos trabalhos que tratam de tal fenômeno nos países pertencentes à terceira onda. $\mathrm{O}$ presente estudo procura trazer este debate para o contexto brasileiro, levando em consideração a produção acadêmica sobre juventude no Brasil. O conceito chave em nossa análise é o de condição juvenil (Abramo, 2011; Abad, 2002; Sposito, 2003), entendido como agregado de características que marcam essa etapa do ciclo de vida e que implicam na negação do acesso as dimensões de produção e reprodução típicas do mundo adulto. A partir da operacionalização empírica desse conceito, nossa intenção nesse trabalho é identificar os possíveis impactos dessa condição juvenil para o ativismo do brasileiro. Ainda que o debate tenha salientado metodologias que abordam a participação política juvenil como um fenômeno multidimensional, produto de efeitos de ciclo de vida, geração e período (Norris, 2002, 2003; Blais et al., 2004; Wass, 2007; Van Ingen, 2008; Gallego, 2009; Castillo, 2008), este estudo tem por objetivo analisar uma única dimensão, a condição juvenil como marcador de transição dos ciclos de vida e seu impacto sobre o ativismo.

Nosso objetivo fundamental, portanto, é verificar os impactos dos marcadores que caracterizam o fim da juventude e a entrada na vida adulta sobre distintas formas de engajamento cívico no contexto brasileiro. Tomamos como referência os estudos sobre ciclos de vida que afirmam que, apesar da permanência residual de valores originados na socialização primária, o desempenho de novos papeis sociais originam novos repositórios de socialização, uma vez que a política é um domínio da vida responsivo a eles. Desta forma procuramos verificar se as diferenças existentes na forma como jovens e adultos interagem com a política, principalmente no que diz respeito a participação, podem ser explicadas pelas distinções originadas nos ciclos de vida. Através de modelos estatísticos, verificamos isoladamente o impacto da condição juvenil, definida pelo casamento e o desempenho de uma atividade produtiva, no engajamento cívico nacional. Levantamos como 
hipótese de trabalho que a condição juvenil oferece restrições e oportunidades para a participação política, de acordo com o tipo de repertório analisado e que a participação convencional impõe mais custos participativos, portanto, menos acessível aos jovens, enquanto a participação não convencional seria mais plural, proporcionando menor diferença no acesso de jovens e adultos.

\section{A política e o ciclo de vida}

As teorias que procuram explicar o ativismo político levando em consideração o desenvolvimento e as mudanças decorrentes do ciclo de vida se originam nos estudos sobre socialização política. Tais investigações objetivam entender como se dão os processos de transmissão de valores e da própria cultura política às gerações mais novas (Sears, 1975) ou ainda, como o conjunto de experiências que são vivenciadas pelo indivíduo no decorrer da vida constroem a identidade de si mesmo e a percepção do sistema político com o qual se relaciona num processo de formação-aprendizagem que se estende ao longo da vida, mas que se consolida nas suas primeiras décadas (Oppo, 1998). Assim a grande preocupação deste campo de estudo é tentar entender como as gerações mais novas vão aprender a interagir com o sistema político, a partir da formação de sua identidade em um processo de aprendizagem que se inicia desde a infância e se constrói ao longo do desenvolvimento do ciclo de vida.

Segundo Sapiro (2004), as primeiras justificativas teóricas para a consolidação deste campo de estudo aparecem em Almond e Verba (1989) e Easton (1979). Segundo estes autores, os processos de socialização política são fundamentais para a consolidação de uma cultura política necessária para o desenvolvimento de um sistema de caráter democrático (Almond e Verba, 1989) ou para gerar mecanismos de suporte apropriado para as funções de entrada - input - de um sistema político (Easton, 1979). Para Sears (1975), a importância destes estudos se assenta no impacto que a permanência de resíduos da socialização primária tem sobre as atitudes e comportamentos dos indivíduos.

A socialização primária corresponde às primeiras décadas de vida do indivíduo, nas quais os valores e crenças que irão orientar as suas atitudes e comportamentos políticos são formados (Oppo, 1998; Inglehart, 1977). Neste período são centrais os papéis 
desempenhados por instituições mediadoras como a escola, a família ou grupos de pares (Flanagan, 2013; Kinder, 2006). Assume-se então que há uma permanência residual de valores, crenças e comportamento incorporados neste período que vai perdurar no decorrer da vida, orientando as atitudes acerca da política (Sears, 1975). Aquilo que se aprende durante estes anos, desta forma, seria relevante para entender o comportamento político por meio da compreensão sobre como se dão os processos de socialização (idem, 1975).

A socialização primária pode ser divida em três períodos distintos, responsáveis pela incorporação de diferentes valores que irão constituir a identidade política do indivíduo. Segundo Oppo (1998), tais períodos correspondem à infância, a adolescência e a entrada no mundo adulto. Como já foi salientado acima, certas instituições adquirem papel central no processo de socialização e a primeira mediação que a criança estabelece com o mundo que o cerca é feita através da família (Almond e Powell, 1972).

Apesar da emergência de temas novos, o enfoque dos estudos de socialização política ainda continua recaindo sobre o papel da transmissão de valores durante os períodos mais suscetíveis da vida, papel desempenhado de forma central pela escola e pela família (Fuks, 2010; Kinder, 2006). Como aponta Sears (1975), os estudos sobre socialização política assumem que os valores incorporados durante a infância e a adolescência vão permanecer durante a vida, formulando as atitudes e comportamentos durante a fase adulta. Mas há uma grande variedade de estudos que questionam esta visão clássica da socialização política, principalmente no que diz respeito às experiências vivenciadas pelo indivíduo fora do período privilegiado para incorporação de valores.

Segundo Sapiro (2004), as descobertas de Jennings e seus colaboradores foram responsáveis por deslocar a ênfase dos estudos sobre socialização política da infância e adolescência para outros períodos da vida. Jennings (1979) define a política como um domínio específico que é responsivo às mudanças nas estruturas de oportunidades ocorridas no decorrer da vida. Neste contexto emergem estudos que passam a procurar entender o papel da transição nas diferentes etapas do ciclo de vida e seus impactos na maneira como os indivíduos vivenciam a política.

Segundo Kinder (2006) o desempenho de novos papéis no decorrer da vida - de filho para pai, de solteiro para casado, de estudante 
para trabalhador - servem como repositórios de socialização, ou seja, "diante de novas normas e ideias, as pessoas mudam" (Idem, 2006, p. 1906). Não há uma negação completa dos valores e comportamentos adquiridos durante os anos mais suscetíveis, muitos deles permanecem no decorrer da vida, mas o papel que os novos repositórios de socialização desempenham é reforçado.

Podemos concluir que as diferentes etapas vivenciadas pelos indivíduos no decorrer da vida, por ser a política responsiva a elas, vão impactar na forma como se vivencia este domínio específico, incidindo inclusive sobre o comportamento político. A partir dessa compreensão se constitui uma perspectiva no campo de estudos da socialização política que considera importante para o entendimento do comportamento político as diferentes etapas que são vivenciadas no decorrer do ciclo de vida.

$\mathrm{O}$ estudo pioneiro que relaciona a idade com a participação política é o trabalho de Lester Milbrath (1977), que identifica um efeito curvilíneo entre estas duas variáveis. Nos achados deste autor ativismo aumenta gradativamente com a idade, sendo relativamente baixo na juventude, atingindo seu pico na idade adulta e voltando a cair na velhice. A vivência das diferentes etapas da vida desempenha funções que influenciam o ativismo, uma vez que tais mudanças alteraram as redes de relacionamento, a disponibilidade de tempo e de recursos materiais. Por outro lado, o avanço da idade representa também um incremento na experiência participativa, dando maiores condições para se efetivar a mesmas (Flanagan, 2013). As etapas do ciclo de vida vão, neste caso, representar rupturas ou continuidades que terão impacto significativo na forma como os indivíduos se relacionam com a política.

Cada etapa do ciclo de vida é pontuada por marcadores de transição (Shanahan, 2000). Estes são descritos como eventos ou características que indicariam os limites ou as fronteiras que são estabelecidas entre cada etapa da vida, indicando o início e o término destas a partir da aquisição ou perda destas características. Nos estudos demográficos, tais marcadores são utilizados como meios de se definir, em termo etários, o início e o término de cada etapa do ciclo de vida (Vieira, 2008).

Highton e Wolfinger (2001) vão apontar seis variáveis nos estudos sobre ciclos de vida que são recorrentes para descrever o processo de transição para a vida adulta: o tempo de permanência em um mesmo 
local de residência, o casamento, a entrada no mercado de trabalho, a posse de uma casa própria, o abandono da casa dos pais e término da escola. Adiciona-se a estas ainda o status parental que, dependendo do período da vida em que ocorre, pode aumentar ou diminuir a incidência de atividades políticas (Oesterle, et. al 2004). O papel da idade como preditora perde sua capacidade explicativa, já que segundo Flanagan (2013), passa a ser relevante apenas como um indicador de desenvolvimento e maturação cognitivos necessários para efetivar a participação.

Tal como descrito no capítulo anterior, este trabalho toma como marco do término da condição juvenil a entrada no mercado de trabalho e a constituição de uma família. Apesar da relevância de outras variáveis que também representam o processo de transição e que podem incidir sobre o ativismo político - como salienta Highton e Wolfinger (2001) - estas duas variáveis representam a possibilidade de vivenciar plenamente a condição adulta, eliminando as restrições em relação às dimensões de produção e reprodução impostas aos jovens. Como observa Abramo (2011) a vivência da condição juvenil não é uniforme na sociedade, variando conforme as estruturas sociais.

O principal ganho analítico da adoção desses conceitos é a possibilidade de analisar as disfunções - em termos etários - que a ideia de juventude adquiriu ao longo do século passado. Desde o final da Segunda Guerra observa-se um processo de extensão desta etapa do ciclo de vida, marcada principalmente pela possibilidade de se vivenciar outras instâncias de socialização para além da escola e da família. Este período de moratória deixa de ser identificado como preparação para a vida adulta (Idem, 2005). Por sua vez a noção de situação remete as diferentes possibilidades de se vivenciar a condição juvenil, dado as diferenças sociais - classe, gênero, etnia que estão estabelecidas no interior da sociedade. A multiplicidade de processos de socialização, marcadas pelas diferentes inserções nas estruturas sociais, pode ser considerada no plano analítico. Esta dicotomia proporciona o reconhecimento de uma condição juvenil única, mas vivenciada através de diferentes situações. Desta forma, se tornou imperativo nos estudos sobre o tema se referir a juventudes, no plural, de modo a considerar a pluralidade de situações juvenis.

Esta condição juvenil também é marcada pela impossibilidade ou restrição de se vivenciar plenamente a condição adulta que, por 
sua vez, engloba o acesso às dimensões de produção, reprodução e de participação. Destaca-se desta forma, como marco do fim da juventude o acesso a tais dimensões, representada na inserção do jovem no mercado de trabalho e na constituição de um núcleo familiar próprio. Dada a impossibilidade de estabelecer de modo preciso um tempo cronológico para o início e término da juventude este trabalho adota esta perspectiva para a definição de juventude.

Ao assumir a existência de uma condição juvenil associada à restrição das dimensões de produção e reprodução, características do mundo adulto, não se excluem da definição outras condicionantes estruturais existentes no interior da sociedade. Pelo contrário, estruturas de classe, etnia e gênero exercem papel significativo na maneira como tal condição é vivenciada ou não. O conceito de juventude não é determinado pela possibilidade de estender a moratória, mas sim pela negação da condição adulta. O que este entendimento do que significa ser jovem permite é justamente reconhecer a diversidade existente nesta etapa do ciclo de vida, entendendo que a condição juvenil é justamente mediada pela situação na qual se encontram os sujeitos dentro da estrutura social.

$\mathrm{O}$ que nos interessa, como parte dos objetivos propostos neste trabalho, é entender os impactos do ser jovem para a participação política. Isto não significa uma generalização simplista de nosso objeto de estudo, uma vez que, por mais que a situação juvenil se apresente da maneira mais variada o possível, a condição juvenil é uma só: a negação da condição adulta. O foco recai, portanto, sobre os marcadores de transição para esta etapa do ciclo de vida, a constituição de um núcleo familiar próprio e a entrada no mercado de trabalho, e sua relação com a participação política.

O casamento, enquanto marco de transição para a vida adulta, é relevante para o contexto deste trabalho porque a transição que ele representa incide claramente sobre o ativismo político. Para Stoker e Jennings (1995) a alteração no status marital acarreta mudanças de duas ordens. A primeira se relaciona com o compartilhamento comum de recursos materiais e sociais. O casamento significa a ampliação das redes de relações sociais, na medida em que há o compartilhamento das mesmas pelos parceiros. Por outro lado, este tipo de relação impõe também constrangimentos materiais e outras restrições que passam também a ser vivenciadas pelo casal. A segunda mudança imposta se relaciona com o processo de aprendizado 
mútuo. O casamento acaba universalizando os valores e atitudes políticas dos dois envolvidos nesta relação (Idem, 1995).

Os achados de Stoker e Jennings (1995) demonstram um decréscimo da participação total ao longo dos anos vivenciados, que se acentua nas coortes etárias inferiores a 24 anos e superiores a 42 anos. Existe um ajuste na forma como ambos os parceiros efetivam a sua participação no início do casamento, de modo a equalizar os níveis de ativismo de modo que se tornem parecidos. Há uma forte tendência de mediação do ativismo político de acordo com as taxas de participação dos parceiros, principalmente em atividades que exigem esforços coletivos ou recorrem a recursos comuns do casal. Ainda que em termos gerais o casamento represente um aumento nos níveis de participação política, o que os estudos destes autores demonstram é que, imediatamente após a constituição do mesmo, há uma queda na participação política, principalmente entre as faixas etárias citadas.

Por sua vez, a entrada no mercado de trabalho como um processo de transição para a vida adulta representa, em primeira instância, o fim de restrições materiais para se efetivar a participação. Segundo o modelo de voluntarismo cívico proposto por Verba, Scholzman e Brady (1995) a participação possui custos para se efetivar. Estes custos se materializam na disponibilidade de tempo, dinheiro e habilidades cognitivas. A entrada no mercado de trabalho representa menos constrangimentos materiais e o desenvolvimento de habilidades cognitivas também se desenvolve nos locais de trabalho. Para estes autores, diversas habilidades necessárias para efetivar a participação política são desenvolvidas no decorrer de toda a vida, principalmente nas atividades coletivas que são desempenhadas pelo indivíduo no trabalho, nas igrejas e organizações. Verba, Scholzman e Brady (1995) vão denominar estes requisitos de habilidades cívicas e entendem que seu desenvolvimento se dá em reuniões onde decisões são tomadas, no planejamento de reuniões, ao escrever uma carta ou realizar um discurso ou apresentação, atividades realizadas em espaços não políticos e fora do período correspondente à socialização primaria.

O modelo descrito por estes autores (Idem, 1995) considera, além de variáveis socioeconômicas e as habilidades cívicas, a disponibilidade de tempo livre como pré-requisito para se efetivar a participação. Algumas circunstâncias como o trabalho em tempo 
integral, possuir um companheiro que também trabalha ou filhos, principalmente em idade pré-escolar, reduzem a disponibilidade de tempo e, consequentemente, afetam o envolvimento político. A adoção integral do modelo do voluntariado cívico, tal como proposto por Verba, Scholzman e Brady (1995), se mostra inviável no contexto deste trabalho, todavia, é pertinente por corroborar as teses sobre o ciclo de vida ao afirmar que as atividades desempenhadas pelos indivíduos fora do período da socialização primária e algumas circunstâncias como o casamento e o trabalho são relevantes para entender a participação política, além de dar pistas para explicar algumas diferenças no envolvimento político de jovens e adultos.

\section{Metodologia}

Para a comprovação de nossa hipótese de trabalho são utilizados dados provenientes do projeto Latinobarómetro ${ }^{1}$ coletados em 1995 , 2000 e 2005 e referentes ao Brasil. A opção por uma abordagem longitudinal requer que as pesquisas tenham níveis de mensuração iguais ou muito próximos para todas as variáveis dependentes do modelo. No caso a opção feita foi por selecionar repertórios de participação convencional e não convencional, além de indicadores de envolvimento com a política em geral. Isto limita o escopo dos anos utilizados, uma vez que as questões nem sempre se repetem a cada coleta de dados. A única justificativa da utilização desta série temporal é a adequação das variáveis dependentes, a saber: interesse em política, frequência de conversa sobre política, sentimento de eficácia do voto como instrumento de transformação social, se já trabalhou para partidos ou candidatos, se já participou de passeatas e bloqueios de tráfego.

Todas estas variáveis possuem níveis distintos de mensuração. Foi adotada uma padronização em que todas as variáveis foram transformadas em dicotômicas para facilitar a exposição dos resultados. Justificamos esta opção metodológica uma vez que as variáveis

1. Projeto de Opinião Pública sobre a América Latina levada a cabo pela Corporação Latinobarómetro, com sede em Santiago, no Chile. A amostra brasileira para o ano de 1995 contou com 1200 casos e um erro amostral de 2,8\%, em 2000 foram 1000 casos e $3,1 \%$ de erro e em 2005 fora 1204 casos com um erro de 2,8\%. 
que representam repertórios não convencionais - participação em passeata e bloqueios de tráfego - são medidas por três categorias: "já fez", "poderia fazer" ou "nunca faria”. Foi considerada apenas a participação efetiva nos modelos estatísticos.

Para a análise são utilizados modelos de regressão logística ou binária. Esta técnica permite calcular as razões de possibilidade odd ratios - de um determinado fenômeno ocorrer (Field, 2009). Tratam-se, portanto, de modelos semelhante aos de regressão linear, mas com o diferencial de permitir a utilização de variáveis categóricas como dependentes. Desta forma, as variáveis dependentes utilizadas neste estudo foram transformadas em dicotômicas e as razões de possibilidade expressam as chances de cada variável independente causar o acionamento de determinado repertório.

O primeiro bloco analisa as variáveis relacionadas à disposição em demonstrar atenção por assuntos relacionados à política, expressa pelas variáveis "interesse em política" e "frequência com que se discute política com os amigos”. Ambas foram representadas por uma escala de quatro pontos ${ }^{2}$. Pela necessidade da utilização de variáveis dicotômicas nos modelos de regressão logística elas foram transformadas em "interessado" e "não interessado"; e "Conversa sobre política" e "não conversa sobre política" a partir dos valores medianos.

No segundo bloco são apresentados os modelos que expressam a participação convencional. O debate internacional gira em torno da possível apatia juvenil em relação à política, tendo como principais indicadores o comparecimento eleitoral e o envolvimento em agências tradicionais de mobilização política, principalmente os partidos políticos. No caso do Brasil, como o voto não é facultativo, selecionamos prox $y^{3}$ para a adesão a esta modalidade de participação o sentimento de eficácia do voto. Nos anos de 1995 e 2005 foi perguntado aos entrevistados se eles acreditavam que o voto é um instrumento que pode transformar as coisas, podendo responder "sim” e "não". Já em 2000 a mesma pergunta foi feita através de uma afirmação e foi coletada a concordância com ela através de uma escala de cinco pontos. Para

2. "muito interessado", "interessado", "pouco interessado" e "nenhum interesse"; "muito frequente", "frequente", "pouco frequente" e "nada frequente".

3. Medida de equivalência que serve como aproximação e representação de outra medida. 
o ano de 2000 foram considerados os dois últimos valores da escala como indivíduos que valorizam o voto como forma de participação.

A segunda variável deste bloco é representada pela frequência da realização de trabalho para um partido ou candidato. Assim como as variáveis do primeiro bloco de análise, esta foi respondida por meio de uma escala. Novamente se considera como participação os valores a partir da média. Na realidade brasileira, o desempenho da função de cabo eleitoral em campanhas muitas vezes é remunerado, o que excluiria a possibilidade de se considerar esta ação como sendo política. Tomar esta premissa como verdadeira excluiria algumas disposições subjetivas como a escolha em desempenhar esta atividade temporária em decorrência de um emprego fixo ou a predisposição em optar trabalhar para um candidato em detrimento de outro. Por conta disto, optamos pela manutenção desta ação como sendo um repertório de ação política.

No último bloco de análise são apresentados os modelos referentes à participação não convencional. Para representar este tipo de repertório são utilizadas as variáveis que questionaram os entrevistados sobre a participação em passeatas e bloqueios de tráfego. Todas elas foram transformadas em binárias tomando como referência a participação, já que esta questão apresenta nos três inquéritos três possíveis respostas - participou, poderia participar e não participaria. Apenas a participação efetiva é aqui considerada.

Um ponto importante da metodologia é a operacionalização do conceito de juventude. Para tal usamos a definição de condição juvenil proposta por Abad (2002) e Sposito (2003). Estes autores definem o jovem como o sujeito sem acesso as dimensões de reprodução e produção, que são características do mundo adulto. Definimos o adulto como aquele que possui pleno acesso a estas dimensões, ou seja, possui seu próprio núcleo familiar - é casado - e executa alguma atividade produtiva. Como marcadores que definem o inicio e o término da juventude estas duas variáveis, estado civil e ocupação, se mostram insuficiente para definir uma coorte etária precisa. Foi adotada a definição legal de jovem expressa no Estatuto da juventude ${ }^{4}$, que corresponde a faixa etária de 16 a 29 anos.

A amostra foi dividida em duas coortes etárias: os jovens, do ponto de vista legal; e todos os outros indivíduos com 30 anos ou mais de

4. Lei número 12852 de 5 de agosto de 2013. 
idade. Está ultima faixa etária é a categoria de referência do modelo, onde as razões de chances descritas são relativas a ela. Por fim, dividimos os jovens de 16 a 29 anos em três categorias: solteiros, estudantes e aqueles que, do ponto de vista teórico, deixaram de ser jovens e já constituíram família e estão trabalhando. Estas variáveis são inseridas como independentes no modelo juntamente com sexo e escolaridade, que atuam como controle. Desta forma podemos comparar os jovens, na perspectiva legal e teórica, e os impactos da condição juvenil no ativismo em geral.

\section{Resultados e discussão}

Tal como descrito acima, o primeiro bloco de análise procura descrever os resultados para os testes envolvendo variáveis que mensuram o envolvimento geral com a política. A Tabela 1 exibe os testes relacionados ao interesse em política. As variáveis inseridas no modelo como controle não demonstram surpresa e condizem com extensa bibliografia que trata do tema sobre a participação política. Segundo Verba, Scholzman e Brady (1995) são os indivíduos que possuem uma posição central na sociedade que tendem a se envolver mais em ações políticas. No modelo abaixo, sexo e escolaridade se confirmam como bons preditores para o interesse em política. Cada ano de estudo aumenta a chances de maior interesse sobre este tema em $18,2 \%$, o que comprova que aqueles com maiores níveis e escolaridade se interessam mais por política. Por sua vez, a variável sexo também se mostrou significativa, o que indica que homens e mulheres possuem níveis diferentes de envolvimento político. As pessoas do sexo masculino possuem quase que o dobro de chances - 83,8\% - de se interessarem por este tema. Isto indica a presença de diferenças significativas no processo de socialização política de homens e mulheres (Flanagan, 2013). Não foram encontradas diferenças estatisticamente relevantes para o ano em que a pesquisa fora realizada, indicando que o interesse em política do brasileiro se manteve estável no decorrer do período analisado.

Os jovens adultos, ou aqueles que do ponto de vista legal se enquadram na faixa etária que corresponde a juventude, mas na perspectiva teórica não podem mais ser definidos como tal, não demonstraram diferenças relevantes em relação a categoria de referência - indivíduos que possuem 30 anos ou mais. Por outro lado 
os jovens que ainda não constituíram uma família possuem menos chances de se interessarem por este tema. Aqueles que possuem entre 16 e 29 anos e que nunca tiveram a experiência do casamento têm quase um terço - -31,1\% - de chances a menos de se interessarem por política. O fato do jovem não estar inserido no mercado de trabalho não se mostrou significante, assim a condição de estudante não impacta no seu interesse por política. A idade isolada não se mostrou significativa para explicar esta varável, uma vez que as coortes etárias possuem níveis parecidos de interesse. O que muda é a adoção ou não de marcadores de transição, neste caso o casamento, que se mostra relevante para explicar o interesse ou não por política. Os jovens solteiros, quando comparados aos adultos e aos adultos jovens, tendem a se interessarem menos por política.

Tabela I - Interesse em Política

\begin{tabular}{lrrrrrr}
\hline & B & S.E. & Wald & df & Sig. & Exp(B) \\
\hline Sexo &, 609 &, 088 & 47,713 & $\mathrm{I}$ &, 000 & I,838 \\
Escolaridade &, 167 &, 010 & 261,292 & $\mathrm{I}$ &, 000 & $\mathrm{I}, 182$ \\
I995 & - & - & 3,957 & 2 &, 138 & - \\
2000 &,- 195 &, 114 & 2,919 & $\mathrm{I}$ &, 088 &, 823 \\
2005 &,- 004 &, 106 &, 001 & $\mathrm{I}$ &, 969 &, 996 \\
30 anos ou mais & - & - & - & - & - & - \\
I6 a 29 Estudante &,- 090 &, 202 &, 199 & $\mathrm{I}$ &, 655 &, 914 \\
I6 a 29 Solteiro &,- 373 &, 111 & 11,316 & $\mathrm{I}$ &, 001 &, 689 \\
I6 a 29 Casado e &,- 139 &, 130 & 1,134 & $\mathrm{I}$ &, 287 &, 870 \\
trabalhando & $-2,67$ &, 125 & 457,312 & $\mathrm{I}$ &, 000 &, 069 \\
Constante & & & & & & \\
Pseudo R2: 0,I44 & & & & &
\end{tabular}

Fonte: Latinobarómetro 1995, 2000 e 2005. Elaboração dos autores.

A Tabela 2 pode trazer algumas revelações sobre este achado. Aqui as variáveis que se mostraram significativas no teste anterior se repetem, com exceção da variável que representa o ano de 2005. Aqui temos um efeito de aumento relacionado ao período em que a pesquisa foi feita. Neste ano começaram a aparecer na mídia os escândalos envolvendo a compra de votos no congresso, com ampla cobertura da mídia (Miguel e Coutinho, 2007), o que pode ter levado ao aumento de conversas sobre este tema em 2005. 
Aqui novamente sexo e escolaridade se mostram significativos, onde ser homem dobra - $129 \%$ - a chances de conversar sobre este tema, assim como cada ano de estudo aumenta em $15 \%$. O jovem adulto e o estudante não demonstram estatísticas relevantes em relação a categoria de referência, o que nos leva a concluir novamente que a idade não representa um preditor adequado para esta variável. Os jovens que ainda não experimentaram uma relação estável tem um redutor de quase metade $--45,4 \%$ - na chance de conversarem sobre política.

Os resultados demonstram que ser solteiro incide negativamente sobre o interesse e a conversa sobre política. Para Stoker e Jennings (1995) uma das mudanças advindas do casamento é a de que os parceiros passam a compartilhar as redes de relacionamento que ambos possuíam antes de se casarem. Outra mudança significativa é a de que ambos os parceiros, após casarem, passam a mediar o envolvimento político um do outro, o que acarreta em uma equalização nas taxas de participação, de modo que ambos tenham níveis parecidos de envolvimento. Isto pode explicar, em parte, as diferenças encontradas entre os indivíduos casados e solteiros no que tange o interesse e conversa sobre política.

Tabela 2 - Conversa Sobre Política

\begin{tabular}{lrrrrrr}
\hline & B & S.E. & Wald & df & Sig. & Exp(B) \\
\hline Sexo &, 831 &, 083 & 99,374 & I &, 000 & 2,297 \\
Escolaridade &, 139 &, 010 & 206,284 & I &, 000 & I,I50 \\
1995 & & & 14,516 & 2 &, 001 & \\
2000 &,- 158 &, 109 & 2,107 & $\mathrm{I}$ &, 147 &, 854 \\
2005 &, 220 &, 099 & 4,991 & $\mathrm{I}$ &, 025 & 1,246 \\
30 anos ou mais & - & - & - & - & - & - \\
16 a 29 Estudante &, 033 &, 196 &, 029 & $\mathrm{I}$ &, 866 & 1,034 \\
16 a 29 Solteiro &,- 605 &, 108 & 31,208 & $\mathrm{I}$ &, 000 &, 546 \\
16 a 29 casado e &,- 094 &, 121 &, 605 & $\mathrm{I}$ &, 437 &, 910 \\
trabalhando & $-2,35$ &, 112 & 445,526 & $\mathrm{I}$ &, 000 &, 095 \\
Constante & & & & & & \\
Pseudo R2:0,138 & & &
\end{tabular}

Fonte: Latinobarómetro 1995, 2000 e 2005. Elaboração dos autores. 
Por outro lado, se o casamento se configura de fato como um marcador de transição para a vida adulta, podemos concluir que há um distanciamento da política por parte dos jovens, na medida em que os solteiros tendem a se interessar menos por política e discutir assuntos relacionados a este tema. $\mathrm{Na}$ hipótese mais otimista sobre este achado, por terem redes de relacionamento reduzidas em relação aos indivíduos que constituíram uma relação estável e não terem uma mediação em seu envolvimento político através de um parceiro, os jovens se encontram em desvantagem se comparados com aqueles que já se tornaram adultos.

Se o interesse e conversa sobre política são mediados pelo estado civil do indivíduo, a participação convencional, por sua vez, sofre influência da condição de inserção no mercado de trabalho, ainda que o sentimento de eficácia do voto não sofra interferência dos marcadores de transição da condição juvenil (Tabela 3). Novamente as diferenças entre os gêneros se mantem, os homens apresentam um quinto de chances a mais de valorizarem o voto como um instrumento de transformação social, cerca de 19,6\%, e um incremento de 49,4\% (Tabela 3) nas chances de se envolverem em atividades de campanha. A escolaridade, como já esperado, também é significativa, e para cada ano de estudo há um aumento de pouco mais de $7 \%$ para ambas as variáveis.

Tabela 3 - Importância Atribuída ao Voto

\begin{tabular}{lrrrrrr}
\hline & B & S.E. & Wald & df & Sig. & Exp(B) \\
\hline Sexo &, 179 &, 071 & $6,26 \mathrm{I}$ & $\mathrm{I}$ &, 012 & $\mathrm{I}, 196$ \\
Escolaridade &, 070 &, 009 & 67,280 & $\mathrm{I}$ &, 000 & $\mathrm{I}, 073$ \\
1995 & - & & $\mathrm{III}, 005$ & 2 &, 000 & - \\
2000 &,- 467 &, 092 & 25,619 & $\mathrm{I}$ &, 000 &, 627 \\
2005 &, 484 &, 085 & 32,203 & $\mathrm{I}$ &, 000 & $\mathrm{I}, 623$ \\
30 anos ou mais & - & - & - & - & - & - \\
16 a 29 Estudante &, 280 &, 169 & 2,748 & $\mathrm{I}$ &, 097 & $\mathrm{I}, 323$ \\
16 a 29 Solteiro &, 089 &, 093 &, 925 & $\mathrm{I}$ &, 336 & $\mathrm{I}, 094$ \\
I6 a 29 casado e &, 075 &, 107 &, 499 & $\mathrm{I}$ &, 480 & $\mathrm{I}, 078$ \\
trabalhando &,- 529 &, 085 & 38,704 & $\mathrm{I}$ &, 000 &, 589 \\
Constante & & & & & & \\
Pseudo R2: 0,072 & & & & &
\end{tabular}

Fonte: Latinobarómetro 1995, 2000 e 2005. Elaboração dos autores 
Sobre as variáveis que representam os marcadores de transição para a vida adulta, estado civil não se mostrou significativo para o sentimento de eficácia do voto (Tabela 3). Já em relação ao envolvimento em atividade de campanha aqueles que ainda não vivenciaram uma relação estável apresentem um redutor de quase um terço $38,8 \%$ - na chance de se acionar este tipo de repertório (Tabela 4). Em relação à ocupação, aqueles que não se inseriram no mercado de trabalho e ainda se mantém apenas como estudantes têm quase $60 \%$ de chances a menos de trabalhar para partidos ou candidatos. Já os jovens adultos, novamente, não demonstraram diferenças significativas em relação ao sentimento de eficácia do voto e no envolvimento em atividades de campanha.

Tomadas em conjunto, estes dois resultados indicam que o envolvimento neste tipo de repertório de participação não é recorrente entre os jovens, pelo contrário, é uma ação tipicamente adulta, uma vez que ambos os marcadores de transição apresentados no modelo se mostraram significativos. Desta forma, os indivíduos que já se constituem como adultos, ou seja, são casados e já estão inseridos no mercado de trabalho, possuem mais chances de se envolverem em atividades de campanha para partidos ou candidatos.

Este resultado permite dois tipos de interpretação. A primeira se refere a um posicionamento crítico em relação à capacidade dos partidos em aglutinarem jovens em suas fileiras. Diversos estudos apontam esta como sendo a principal causa da constante queda nas taxas de filiação partidária. Estruturas burocráticas e hierárquicas, bem como processos de decisões centralizados, afastariam os jovens dos partidos políticos, levando-os a um posicionamento mais crítico em relação a essas instituições (Dalton, 2012). Desta forma a organização verticalizada dos partidos não consegue representar os anseios juvenis, que perpassam os valores de auto expressão e a demanda por uma participação ativa nos processos de decisões. É uma tarefa ingrata convencer um jovem a doar seu tempo para a militância e seus escassos recursos para custear as atividades do partido sendo que ele não participará ativamente das decisões partidárias.

[...] a participação é mais influenciada por variáveis relacionadas à centralidade social dos cidadãos do que por mudanças nas suas prioridades valorativas, o que leva à conclusão de que a transposição do modelo explicativo sugerido por Inglehart para o cenário latinoamericano 
é problemática e deve ser avaliada criticamente. (Ribeiro e Borba, 2010, p. 28).

A tese da centralidade é retirada do modelo do voluntariado cívico proposto por Verba, Scholzman e Brady (1995). Segundo estes autores a participação envolveria um conjunto de custos materiais, cognitivos e de disponibilidade de tempo, o que favoreceria o engajamento de indivíduos que ocupam posições centrais dentro da estrutura social. Os resultados da Tabela 4 demonstram que são os homens, com maior escolarização, casados e inseridos no mercado de trabalho que possuem maiores chances de acionarem este repertório. Este dado vincula nitidamente a participação em atividades de campanha às mudanças do ciclo de vida. Os jovens, por não ocuparem uma posição central na sociedade, tendem a se envolverem menos em atividades de campanha, mas na medida em que se integram plenamente a vida adulta, as chances de acionarem este repertório podem ser equalizadas.

Tabela 4 - Participação em Atividades de Campanha

\begin{tabular}{|c|c|c|c|c|c|c|}
\hline & B & S.E. & Wald & $d f$ & Sig. & $\operatorname{Exp}(B)$ \\
\hline Sexo & ,402 &, 129 & 9,615 & 1 & ,002 & 1,494 \\
\hline Escolaridade & ,068 &, 014 & 22,863 & I & ,000 & $|, 07|$ \\
\hline 1995 & & & 5,962 & 2 & ,051 & \\
\hline 2000 &,- 302 &, 164 & 3,398 & I & ,065 & ,739 \\
\hline 2005 &,- 352 & , 155 & $5,17 \mid$ & I & ,023 & ,703 \\
\hline 30 anos ou mais & - & - & - & - & - & - \\
\hline 16 a 29 Estudante &,- 950 & ,476 & 3,988 & I & ,046 & ,387 \\
\hline 16 a 29 Solteiro &,- 490 & , I75 & 7,837 & I & ,005 &, 612 \\
\hline $\begin{array}{l}16 \text { a } 29 \text { casado e } \\
\text { trabalhando }\end{array}$ &, 012 & , 182 &, 004 & I & ,949 & 1,012 \\
\hline Constante & $-2,81$ &, 160 & 308,621 & I & , 000 &, 060 \\
\hline Pseudo R2: 0,033 & & & & & & \\
\hline
\end{tabular}

Fonte: Latinobarómetro 1995, 2000 e 2005. Elaboração dos autores.

Por fim, a participação não convencional apresenta resultados intrigantes (Tabela 5 e 6). A escolaridade se manteve significativa para os dois repertórios analisados, sendo que cada ano de estudo acarreta aumento de $13,4 \%$ e $16,8 \%$ nas chances do indivíduo 
participar de passeatas e bloqueios de tráfego, respectivamente. A variável sexo só se mostra significativa para a participação em passeatas, sendo que os homens possuem chances $25,6 \%$ maiores de acionarem este repertório. A condição juvenil não se mostra significativa, o que indica que adultos e jovens tendem a participar de passeatas em níveis parecidos.

Em relação à participação em bloqueios de tráfego, as distinções de gênero não são verificadas, o que indica que este repertório tem sido acionado de forma mais ou menos equivalente entre homens e mulheres. Outro dado relevante é que os indivíduos que ainda não constituíram uma família possuem $64,9 \%$ de chances maiores de acionarem este repertório, o que indica que a participação em bloqueios de tráfego é uma ação tipicamente juvenil. Este repertório, pelo menos no período analisado, se caracteriza por ser mais igualitário na medida em que a diferença na participação de homens e mulheres não se mostrou significativa e os jovens tendem a acionar este repertório mais que os adultos.

Aqui, como nos modelos anteriores, a idade não se mostra um preditor adequado. Os jovens adultos tem o envolvimento em bloqueios de tráfego parecido com a categoria de referência. As passeatas parecem ser um repertório que não possui restrições quanto às etapas do ciclo de vida, ainda que as diferenças por gênero e escolaridade se mantenham. Para os dois repertórios não convencionais analisados há um redutor no ano de 2005. Experiências relacionadas a pluralização da representação (Lüchmann, 2007; Lavale et. al, 2006) podem estar relacionadas com este fenômeno, uma vez que se constituem como canais privilegiados de interlocução entre a sociedade civil e o Estado, aliviando as tensões que geram protestos.

Se tomarmos em conjunto os resultados dos testes referentes à participação convencional e não convencional, uma análise superficial poderia sugerir que no período analisado estaríamos vivenciando um fenômeno parecido com o que ocorre em países de economia pós-industrial, uma vez que os adultos (ou as gerações mais velhas) possuem maior apegado às formas convencionais de participação, expressa pela maior chance dos adultos em se envolverem em atividades de campanha, enquanto os jovens são mais propícios a acionarem repertórios não convencionais de participação política, tal como a teoria do desenvolvimento humano preconiza (Inglehart e Welzel, 2005). 
Tabela 5 - Participação em Passeatas

\begin{tabular}{|c|c|c|c|c|c|c|}
\hline & B & S.E. & Wald & $d f$ & Sig. & $\operatorname{Exp}(B)$ \\
\hline Sexo & ,228 & ,089 & 6,597 & 1 & 010 & 1,256 \\
\hline Escolaridade & , 126 & 010 & 147,074 & I & ,000 & 1,134 \\
\hline 1995 & - & - & $|17,33|$ & 2 & ,000 & - \\
\hline 2000 &,- 560 & , 108 & 26,708 & I & ,000 & (571 \\
\hline 2005 & $-1,25$ &, 115 & 117,079 & 1 & ,000 & ,287 \\
\hline 30 anos ou mais & - & - & - & - & - & - \\
\hline 16 a 29 Estudante &,- 084 & , 197 & , 179 & I & ,672 & 920 \\
\hline 16 a 29 Solteiro &,- 033 &, 110 & ,089 & I & ,765 & 968 \\
\hline $\begin{array}{l}16 \text { a } 29 \text { casado e } \\
\text { trabalhando }\end{array}$ &,- 020 & , 132 & ,022 & 1 & , 881 & ,980 \\
\hline Constante & $-1,845$ & , 109 & 285,628 & I & ,000 & , 158 \\
\hline Pseudo $R^{2}: 0,117$ & & & & & & \\
\hline
\end{tabular}

Fonte: Latinobarómetro 1995, 2000 e 2005. Elaboração dos autores.

Mas existem alguns empecilhos para assumir esta premissa. O primeiro é de natureza metodológica. Este estudo não permite determinar se existe uma correlação entre a participação política e os valores pós-materialistas, principal atributo das mudanças nos padrões de comportamento político descritos por Inglehart e seus colaboradores. Para tal, seria necessário um intervalo de tempo maior e a construção de modelos que considerassem esta variável. Segundo, a adesão destes valores no Brasil ainda se mostra relativamente baixa, principalmente devido às desigualdades sociais ainda existentes (Ribeiro, 2011), o que seria insuficiente para ocasionar um efeito generalizado.

A tese da centralidade derivada do modelo do voluntariado cívico de Verba, Scholzman e Brady (1995) se mostrou coerente para explicar a participação convencional. São indivíduos que possuem uma posição central na estrutura social que tendem a acionar com maior frequência este tipo de repertório, que nos leva a recorrer à própria natureza da ação de participar em um bloqueio de tráfego para explicar a tendência dos jovens em tomar parte destas ações. Dentre todos os repertórios analisados, este representa o menor porcentual médio de adesão, sendo que apenas 4,1\% dos entrevistados nos três anos da pesquisa se já haviam participado deste tipo de ação. 
Tabela 6 - Participação em Bloqueios de Tráfego

\begin{tabular}{|c|c|c|c|c|c|c|}
\hline & $B$ & S.E. & Wald & $d f$ & Sig. & $\operatorname{Exp}(B)$ \\
\hline Sexo & ,272 & , 182 & 2,250 & I & , I34 & 1,313 \\
\hline Escolaridade & , 155 & ,021 & 54,126 & I &, 000 & 1,168 \\
\hline 1995 & & & 28,107 & 2 & ,000 & \\
\hline 2000 &,- 459 & ,207 & 4,918 & I & ,027 & ,632 \\
\hline 2005 & $-1,39$ & ,264 & 27,993 & I &, 000 & ,247 \\
\hline 30 anos ou mais & - & - & - & - & - & - \\
\hline 16 a 29 Estudante &,- 392 & ,396 & ,977 & I & ,323 & ,676 \\
\hline 16 a 29 Solteiro &, 500 & ,205 & 5,969 & I &, 015 & 1,649 \\
\hline $\begin{array}{l}16 \text { a } 29 \text { casado e traba- } \\
\text { Ihando }\end{array}$ & ,265 & ,272 & ,950 & 1 & ,330 & $\mathrm{I}, 303$ \\
\hline Constante & $-4,30$ & ,260 & 274,599 & 1 &, 000 &, 014 \\
\hline Pseudo R2: 0,102 & & & & & & \\
\hline
\end{tabular}

Fonte: Latinobarómetro 1995, 2000 e 2005. Elaboração dos autores.

Quando importantes vias de transito são bloqueadas, o Estado frequentemente aciona o aparato policial para promover a sua desobstrução e o risco de confronto entre manifestantes e policiais se torna eminente. Nestes casos o uso da força é recorrente, o que traz grandes chances de lesões, ferimentos e prisões de manifestantes. Desta forma, os custos participativos entre os adultos são relativamente mais altos de comparados com os jovens. O risco de detenção pode ocasionar a perca de status social e as lesões podem incapacitar o indivíduo a ponto de impossibilitá-lo de trabalhar, colocando em risco a segurança material de sua família. Com uma posição menos definida no interior da sociedade e sem a preocupação com a manutenção de um lar, os jovens teriam menos custos em tomar parte neste tipo de ação.

As variáveis de controle inseridas no modelo se mostraram significativas para todas as modalidades de participação, com exceção da variável de gênero para o repertório de bloqueio de tráfego. Este repertório de participação parece ser mais inclusivo à participação de mulheres, já que não apresenta resultados estatisticamente significantes. A educação por sua vez se mostrou significante para todos os repertórios e cada ano de estudo produz incremento nas chances de efetivar a participação, o que já era esperado. Este resultado condiz com extensa bibliografia que salienta a importância desta variável e sua relação com o ativismo político (Almond e Verba, 1989; Borba e Ribeiro, 2010; Dalton, 2009). 
Por mais que os resultados envolvendo as variáveis de controle sócio demográfico e sua influência sobre o conjunto de variáveis dependentes já fosse esperado, este achado ajuda a eliminar as relações espúrias que poderiam ocorrer com as duas variáveis independentes que foram utilizadas para representar a condição juvenil. A despeito da importância da educação e do gênero e de seu caráter preditor para explicar a participação, os resultados envolvendo a relação entre o ciclo de vida e a participação se torna ainda mais relevantes.

\section{Conclusão}

Este trabalho procurou analisar os efeitos de ciclo de vida para verificar os seus impactos sobre o ativismo juvenil. Ao trabalhar com três anos distintos de coletas de dados em uma mesma base e não inserir coortes etárias no modelo, verificamos apenas os efeitos da condição juvenil, definida pelo casamento e a entrada no mercado de trabalho, na participação política nos repertórios selecionados. Os resultados expostos acima demonstram que a participação no Brasil é mediada por eventos relacionados ao ciclo de vida do indivíduo, uma vez que os marcadores de transição se mostraram eficazes para a maioria dos repertórios analisados.

Se existem diferenças entre a participação política do jovem e do adulto, estas decorrem dos efeitos proporcionados pelas transições inerentes ao ciclo de vida. Ao assumir novos papéis dentro da estrutura social os indivíduos passam a ter acesso a novos repertórios de socialização, que por sua vez condicionam a sua participação, remodelando-a para se adaptar ao novo contexto no qual se insere, como é o caso da participação convencional. Aqueles que ocupam posições centrais no interior da sociedade possuem mais chances de se envolveram em atividades de campanha eleitoral, fato possível apenas com o ingresso na vida adulta.

Por sua vez, ao atingirem a maturidade e constituírem dependentes, a participação não convencional se torna mais custosa, na medida em que se coloca em jogo a manutenção de sua família e de sua posição social. Outra possível interpretação é que de que além de recursos cognitivos, a disponibilidade de tempo seja uma exigência maior do que a posse de recursos financeiros, o que facilitaria o jovem a se engajar nestes repertórios. Assim estas diferenças se relacionam 
de forma nítida com o desenrolar de eventos relacionados ao ciclo de vida.

\section{Referências}

ABAD, M. (2002). Las políticas de juventud desde la perspectiva de la relación entre convivencia, ciudadanía y nueva condición juvenil. Ultima décad, vol.10, n.16, $117-52$.

ABRAMO, H. W. (2011). Condição Juvenil no Brasil Contemporâneo. In: ABRAMO, H. W.; BRANCO, P. P. M. (orgs.) Retratos da Juventude Brasileira: Analises de uma Pesquisa Nacional. São Paulo: Editora Fundação Perseu Abramo.

ALMOND, G. A.; POWELL, G. B. (1972) Uma teoria de política comparada. Rio de Janeiro: Zahar.

ALMOND, G.; VERBA, S. (1989). The Civic Culture: political attitudes and democracy in five nations. New York: Sage.

BLAIS, A. (2004). et al. Where does turnout decline come from?. European journal of political research, v. 43, n. 2, 221-36.

BORBA, J.; RIBEIRO, E. A. (2010). Participação convencional e não convencional na América Latina. Revista Latino-Americana de Opinión Pública, v. 1, 53-76.

CASTILLO, A. M. J. (2008). Trayectorias de participación política de la juventud europea: : Efectos de cohorte o efectos de ciclo vital? Revista de Estudios de Juventud, n. 81, p. 67-93.

DALTON, R. J. (2009). The good citizen: How a younger generation is reshaping American politics. Washington: CQ Press.

DALTON, R. J. (2012). The Apartisan American: Dealignment and Changing Electoral Politics. Washington: CQ Press.

EASTON, D. (1979). A systems analysis of political life. Chicago, IL: University of Chicago Press.

FIELD, A. (2009) Descobrindo a estatística usando o SPSS. São Paulo: Armed.

FLANAGAN, C. A. (2013). Teenage Citizens: The Political Theories of the Young. New York: Harvard University Press.

FUKS, M. (2010). Efeitos diretos, indiretos e tardios: trajetórias da transmissão intergeracional da participação política. Trabalho apresentado no $34^{\circ}$ Encontro Anual da Anpocs. Caxambu, 25-29 de Outubro.

GALLEGO, A. (2009). Where else does turnout decline come from? Education, age, generation and period effects in three European countries. Scandinavian Political Studies, v. 32, n. 1, 23-4.

HENN, M.; et al. (2002). A generation apart? Youth and political participation in Britain. The British Journal of Politics \& International Relations, v. 4, n. 2, p. 167-92. 
HIGHTON, B.; WOLFINGER, R. E. (2001). The first seven years of the political life cycle. American Journal of Political Science, p. 202-9.

INGLEHART, R. (1977). The silent revolution. Princeton: Princeton University Press.

INGLEHART, R.; WELZEL, C. (2005). Modernization, cultural change, and democracy: The human development sequence. New York: Cambridge University Press.

INGLEHART, R; CATTERBERG, G. (2002). Trends in political action: The developmental trend and the post-honeymoon decline. International Journal of Comparative Sociology, v. 43, n. 3-5, p. 300-16.

JENNINGS, M. K. (1979). Another look at the life cycle and political participation. American Journal of Political Science, v. 23, n.4 p. 755-71.

KINDER, D. R. (2006). Politics and the life cycle. Science, v. 312, n. 5782, p. 1905-8.

LAVALLE, A. et al. Democracia, pluralização da representação e sociedade civil. Lua Nova, v. 67, n. 67, p. 49-103, 2006.

LÜCHMANN, L. H. H. A representação no interior das experiências de participação. Lua Nova, v. 70, p. 139-170, 2007.

MIGUEL, L. F.; COUTINHO, A. A. A crise e suas fronteiras: oito meses de "mensalão” nos editoriais dos jornais. Opinião pública, v. 13, n. 1, p. 97-123, 2007.

MILBRATH, L. W. (1977). Political Participation: How and Why Do People Get Involved in Politics? Chicago: Rand McNally College Publishing.

NORRIS, P. (2002). Democratic phoenix: Reinventing political activism. New York: Cambridge University Press.

NORRIS, P. (2003). Young People \& Political Activism: From the Politics of Loyalties to the Politics of Choice? Disponível em: http://www.pippanorris.com. 17/02/2012.

OESTERLE, S.; et al. (2004) Volunteerism during the transition to adulthood: A life course perspective. Social Forces, v. 82, n. 3, p. 1123-49.

OPPO, A. (1998). Socialização política. In: BOBBIO, N. (org) Dicionário de Política. Brasília: Editora UNB.

PUTNAM, R. D. (2001). Bowling alone. New York: Simon \& Schuster.

RIBEIRO, E. A. (2011). Valores Pós-Materialistas e Cultura Politica no Brasil. Maringá: Eduem.

RIBEIRO, E. A.; BORBA, J. (2010). Participação e pós-materialismo na América Latina. Opinião Publica, v. 16, n. 1, p. 28-64.

SAPIRO, V. (2004). Not Your Parents Socialization: Introduction for a New Generation. Annual Review of Political Science, v. 7, p. 1-23.

SEARS, D. O. (1975). Political socialization. In: GREENSTEIN, Fred I.; POLSBY, Nelson W. (Org.). Handbook of political science, v. 2, p. 93-153. Boston: Addison Wesley Publishing Company. 
SHANAHAN, M. J. (200). Pathways to adulthood in changing societies: Variability and mechanisms in life course perspective. Annual review of sociology, p. 667-92.

SOUZA, R. M. (2008). O Discurso do Protagonismo juvenil. São Paulo: Paulus.

SPOSITO, M. P. (2003). Os jovens no Brasil: desigualdades multiplicadas e novas demandas politicas. São Paulo: Ação Educativa.

STOKER, L.; K JENNINGS, M. K. (1995). Life-cycle transitions and political participation: The case of marriage. American Political Science Review, p. 421-33.

STRATE, J. M. et al. (1989). Life span civic development and voting participation. The American Political Science Review, p. 443-64, 1989.

VAN INGEN, E. (2008). Social Participation Revisited Disentangling and Explaining Period, Life-Cycle and Cohort Effects. Acta Sociologica, v. 51, n. 2, p. 103-21.

VERBA, S. SCHLOZMAN, K. L.; BRADY, H. E. (1995). Voice and equality: Civic voluntarism in American politics. Cambridge: Harvard University Press.

VIEIRA, J. M. Transição para a vida adulta no Brasil: análise comparada entre 1970 e 2000. Revista Brasileira de Estudos de População, v. 25, n. 1, p. 27-48, 2008.

WASS, H. (2007). The effects of age, generation and period on turnout in Finland 1975-2003. Electoral studies, v. 26, n. 3, p. 648-59. 